\title{
Kadın cinsel fonksiyon bozukluklarında kanıta dayalı tedavi seçenekleri
}

\author{
Evidence-based therapy options for female sexual dysfunction
}

Ercan Yeniఠ

\section{öz}

Kadın cinsel fonksiyon bozukluğu; "istek, uyarılma, orgazm ve çözülme dönemlerinden oluşan cinsel yanıt döngüsünün bozulması ve/veya cinsel ilişki sırasında ağrı duyulması" olarak tanımlanmaktadır. Diagnostic and Statistical Manual of Mental Disorders V'te cinsel istek/uyarılma bozukluğu, kadın orgazm bozukluğu ve genitopelvik ağrı/penetrasyon bozukluğu şeklinde sınıflandırılmaktadır. Tedavide bu alanları hedef alacak şekilde planlanmaktadır. Kanıta dayalı tedaviler, tedaviye karar verirken en iyi kanıtların, dikkatli, açık ve akıllıca kullanılması esasına dayanan uygulamalardır. Bu kapsamda günümüzde kadın cinsel fonksiyon bozukluklarında kanıta dayalı tedaviler son derece sınırlıdır. Hipoaktif cinsel istek bozukluğunda FDA onaylı tek ilaç flibanserindir. Postmenopozal genito-üriner sendroma bağlı disparoni için FDA onaylı birkaç ürün vardır. Kadınlarda cinsel uyarılma ve/veya orgazm bozuklukları için onaylanmış farmasötik bir ürün yoktur. Halen kadın cinsel işlev bozukluğunu hedef alan tedavilerin çoğu ilaçların endikasyon dışı kullanımları şeklindedir.

Anahtar Kelimeler: kadın, cinsel fonksiyon bozukluğu, kanıta dayalı tedavi

\section{Gíriș}

Temel olarak cinsel fonksiyon bozukluğu; "istek, uyarılma, orgazm ve çözülme dönemlerinden oluşan cinsel yanıt döngüsünün bozulması ve/veya cinsel ilişki sırasında ağrı duyulması"olarak tanımlanmaktadır. Bu durumun tek başına var olması kişiyi sorunlu olarak kabul etmek için yeterli değildir. Var olan bu durumun kişisel stres ve/veya partner ile ilişkilerde sorun olarak algılanıyor olması da gereklidir. Tanımlamanın bütünüyle ortaya konabilmesi için var olan durumun pirimer mi yoksa sekonder mi olduğu, yaygın mı yoksa durumsal mı olduğu ve devamlı mı yoksa tekrarlayıcı mı olduğu da kayıt altına alınmalıdır. ${ }^{[1,2]}$

Ankara Şehir Hastanesi Onkoloji Hastanesi Başhekimliği, Ankara, Türkiye

Yazışma Adresi/ Correspondence:

Prof. Dr. Ercan Yeni

Ankara Şehir Hastanesi Onkoloji Hastanesi Başhekimliği Ankara, Türkiye

Tel. $\quad$ +90506744 1454

E-mail: ercanyeni@gmail.com

Geliş/ Received: $\quad 16.06 .2019$

Kabul/ Accepted: 10.07.2019

\section{ABSTRACT}

Female sexual dysfunction is defined as disruption of the sexual response cycle consisting of desire, arousal, orgasm and resolution and/or pain during sexual intercourse. Female sexual dysfunction is classified as female sexual interest or arousal disorder, female orgasmic disorder and genitopelvic pain or penetration disorder in DSM V. The treatment is planned to target these areas. Evidence-based therapies are based on the careful, clear and wise use of the best evidence when deciding treatment. In this context, evidence based therapies in female sexual dysfunction are extremely limited. The only FDA approved drug in hypoactive sexual desire disorder is flibanserin. There are several FDA approved products for the dyspareunia associated with postmenopausal genito-urinary syndrome. There is no pharmaceutical product approved for sexual arousal and/or orgasmic disorders in women. Most of the treatments currently targeting female sexual dysfunction are off-label use.

Keywords: female, sexual dysfunction, evidence-based therapy

Kadın Cinsel Fonksiyon Bozukluğu'da benzer şekilde tanımlanmakta olup Diagnostic and Statistical Manual of Mental Disorders (DSM) IV ve V versiyonlarında Tablo 1 'de görülen şekilde sınıflandırılmaktadır. ${ }^{[2,3]}$

Tablo 1. DSM-IV ve DSM-V'e göre kadın cinsel fonksiyon bozukluğu sınıflandırması

\begin{tabular}{|l|c|}
\hline DSM-IV & \multicolumn{1}{|c|}{ DSM-V } \\
\hline Hipoaktif cinsel istek bozukluğu & $\begin{array}{c}\text { Cinsel istek/uyarılma } \\
\text { bozukluğu }\end{array}$ \\
\hline $\begin{array}{l}\text { Öznel cinsel uyarılma bozukluğu } \\
\text { Genital cinsel uyarıma bozukluğu } \\
\text { Kombine genital-öznel uyarılma } \\
\text { bozukluğu } \\
\text { Israrlı cinsel uyarılma bozukluğu }\end{array}$ & \\
\hline Kadın orgazm bozukluğu & Kadın orgazm bozukluğu \\
\hline $\begin{array}{l}\text { Disparoni } \\
\text { Vajinismus } \\
\text { Cinsellikten tiksinti duyma bozukluğu }\end{array}$ & $\begin{array}{c}\text { Genitopelvik ağrı/ } \\
\text { penetrasyon bozukluğu }\end{array}$ \\
\hline DSM, Diagnostic and Statistical Manual of Mental Disorders. \\
\hline
\end{tabular}




\section{Kanıta Dayalı Tedavi}

İngilizce literatürde "evidence-based medicine", Türkçe literatürde "kanıta dayalı tıp" olarak adlandırılan ve "hastaların tedavi sürecinde karar verirken en iyi kanıtların, dikkatli, açık ve akıllıca kullanılması' ${ }^{[4]}$ esasına dayanan uygulamalar kapsamında değerlendirecek olursak günümüzde kadın cinsel fonksiyon bozukluklarında kanıta dayalı tedavi seçenekleri şunlardır. ${ }^{[5]}$

\section{Mevcut (Onay Almıș) Tedaviler}

- Hipoaktif cinsel istek bozukluğu (HSDD): şu anda Amerikan Food and Drug Administration (FDA) onaylı tek bir ilaç vardır; flibanserin (Addyi). Bu ürününde henüz European Medicines Agency (EMA) onay1 yoktur.

- Postmenopozal genito-üriner sendroma bağlı disparoni için FDA onaylı tedaviler vardır.

- Kadınlarda cinsel uyarılma ve/veya orgazm bozuklukları için onaylanmış farmasötik ürün yoktur.

- Halen kadın cinsel işlev bozukluğunu hedef alan tedavilerin çoğu ilaçların endikasyon dışı kullanımları şeklindedir.

\section{Kadında Hipoaktif Cinsel isstek Bozukluğu (HSDD)'da Mevcut Tedaviler}

\section{Flibanserin (Addyi)}

Hormonal özellikte olmayan, merkezi etkili bir ajandır. Postsinaptik 5-HT1A reseptörlerine karşı agonistik, 5-HT2A reseptörlerine karşı antagonistik ve dopamin D4 reseptörlerinin karşı ise zayıf parsiyel agonistik etkisinin olduğu gösterilmiştir. Kümülatif etkisi sonucunda beyinde dopamin ve norepinefrin aktivitesini arttırırken, serotonin aktivitesini azaltmaktadır. ${ }^{[6]} 2015$ yılında premenopozal kadınlarda edinilmiş jeneralize tipte hipoaktif cinsel istek bozukluğunun tedavisi için FDA onayı aldı. ${ }^{[7]}$ Hali hazırda EMA onayı yoktur. Her gece $100 \mathrm{mg}$ dozunda oral yoldan uygulanır. Birkaç hafta da etkisinin başladığı gösterilmiştir. Alkolle birlikte alındığında ciddi hipotansiyon ve senkop riski var. Premenopozal HSDD'li kadınların yaklaşık $\% 50$ 'sinde cinsel istek seviyelerinde artış ve istek azlığına bağlı sıkıntıda plaseboya göre anlamlı iyileşme söz konusudur. ${ }^{[5]}$ Çalışmalarda postmenopozal kadınlarda da benzer etkinlik gösterilmiştir. Ancak bu grup için henüz endikasyon onayı yoktur. ${ }^{[8]}$ HSDD için onaylı ilk ve tek ilaç olmasına rağmen, beklenen düzeyde yaygın kullanıma ulaşmamıştır. Beklenen sıklıkta kullanılamamasının sebepleri olarak mide bulantısı (en sık), sedasyon, baş dönmesi ve yorgunluk gibi yan etkilerin varlığı, etkinin beklentileri karşılamaması, ilacın hemen hiçbir ülkede sigorta kapsamında ödenmemesi ve birçok kadının bu tedaviyi karşılayamaması durumları öne çıkmaktadır. ${ }^{[5]}$

\section{Kadında Genitopelvik Ağrı / Penetrasyon Bozukluğu - Disparoni - Mevcut Tedaviler}

\section{Östrojen}

Postmenopozal vulvo-vajinal atrofi ve bunula ilişkili disparoni yakınması, yaygın bir kadın cinsel fonksiyon bozukluğu tipidir. Bu kadınların tedavileri için günümüzde FDA onaylı birkaç östrojen bazlı tedavi seçeneği mevcuttur. Östrojenin topikal formlarda lokalize kullanımı ile sistemik etkisi minimalize edilir. Bu sayede östrojenin, meme ve endometriyal dokuya daha düşük düzeylerde geçişi sağlanır. Bu beklentinin bir karşılığı olarak çalışmalarda lokalize östrojen kullanımı ile endometrial hiperplazi veya karsinom riskinde artış olmadığı gösterilmiştir. ${ }^{[5]}$ Konjuge östrojenden oluşan topikal vajinal kremler (Estrace ve Premarin), estradiol vajinal halka (Estring) ve estradiol vajinal tablet (Vagifem) bu alanda uzun yıllardır kullanılan ruhsatlandırılmış ürünlerdir. ${ }^{[5,9]}$

\section{Imvexxy (Estradiol)}

Postmenopozal vulvo-vajinal atrofi ile ilişkili orta/şiddetli disparonisi olan 764 hastada üç ayrı dozda intravajinal estradiol, plaseboya karşı çift kör modelde çalışıldı (REJOICE). 12 hafta, 4, 10, $25 \mu \mathrm{g}$ intravajinal estradiol plasebo ile karşılaştıııldı. Disparoninin şiddet skorları her üç estradiol grubunda da plaseboya göre çok daha anlamlı derecede düşük bulundu. Bu çalışmanın sonuçları ile FDA onayı aldı. ${ }^{[10]}$ Günlük pratikte önerilen doz 2 hafta boyunca günde bir kez $4 \mu \mathrm{g}$, daha sonra her 3-4 günde bir kez $10 \mu \mathrm{g}$ kapsüldür. Uygulamada, herhangi bir aplikatör gerektirmeden yumuşak kapsül vajinaya yaklaşık $4-5 \mathrm{~cm}$ e yerleştirilir. $^{[9,11]}$

\section{Ospemifene (Osphena)}

Hormonal olmayan seçici bir östrojen reseptör modülatörüdür. Postmenopozal VVA ilişkili disparoni tedavisinde 2013 'de onaylı. 12 hafta, günde $60 \mathrm{mg}$ ospemifen alan kadınların yaklaşık \%75'inde vajinal kuruluk ve disparonide iyileşme gösterilmiştir. Ospemifenin vajinal epitelde östrojen benzeri etkileri olduğu ancak endometriyum, kardiyovasküler, meme veya kemik üzerinde önemli bir yan etkisinin olmadığı gösterilmiştir. En sık yan etkisi sıcak basmaları olup yaklaşı 4 . haftada pik yapar. Ancak tedaviye devamı çok etkilemediği rapor edilmiştir. ${ }^{[5,12]}$ 


\section{Prasterone (Intrarosa)}

Androjen ve östrojen öncüsü olan dehidroepiandresteron (DHEA). Postmenopozal kadınlarda VVA kaynaklı disparoni tedavisi için 2016 yılında onaylandı. Yatmadan önce günlük vajinal insert tb olarak uygulanır. İntravajinal uygulama sistemik yan etkilerini minimalize eder. En sık bildirilen yan etki vajinal akıntıdır. İki randomize, çift kör çalışmada disparoni derecesinde anlamlı düşüşler gösterildi. HSDD için onayı yok, bu alanda ümit vaat eden faz 3 çalışma var. ${ }^{[5,13]}$

\section{Faz (2-3) Çalıșmaları Devam Eden Tedaviler}

Androjenler

Günümüzde, kadınlarda HSDD tedavisinde FDA tarafından onaylanmış androjen preparatı yoktur. Androjenler kadınlarda genellikle düşük cinsel istek ve uyarılmayı düzeltmek için endikasyon dişı kullanılır. Suprafizyolojik dozlarda, özellikle oral alımlarda bir kısmı kalıcı, bir kısmı geri dönüşümlü ciddi yan etkiler rapor edilmektedir. Sistemik etkileri minimalize etmek ve düşük dozlarda etkinliği artırmak için topikal formların geliştirilmesi çalışmaları sürmektedir. ${ }^{[5]}$

Intrinsa, testosteron yaması, FDA onayı için tüm kriterleri karşılamış 5 yıllık güvenlik çalışmasını beklemektedir. Ürün bu süreçte EMA dan onay aldı. Tedavi süresi boyunca orgazmik fonksiyonda istatistiksel olarak anlamlı bir artış, cinsellikle ilgili sıkıntılarda azalma belirlenmiştir. Ciddi herhangi bir olumsuz yan etki bildirilmemiştir. ${ }^{[5,14]}$

Mart 2017 itibariyle kadın cinsel fonksiyon bozukluğu tedavisinde sinerjistik etki beklentisi ile testosteron içeren iki farklı kombinasyon çalışıldı. Testosteron+sildenafil (Lybrido): sildenafil ile erektabıl genital organ/yapılarda kan akışı artışı sağlanarak cinsel isteğin yanısıra uyarılma cevabınında artacağı varsayımı ile ve testosteron+buspirone (Lybridos) ise 5-HT1A reseptör agonisti olan buspironun cinsel inhibisyonu azaltıp testosteronun etkisini potansiyelize edeceği varsayımı ile kombine tedavileri planlandı. Randomize, çift kör plasebo kontrollü çalışmada 21-70 yaş arası istek-uyarılma azlığı olan 497 kadın plasebo, testosteron, sildenafil, buspiron, testoteron+sildenafil ve testosteron+buspiron kollarına randomize edildi. Her iki kombinasyon kolunda da kullanımın güvenliği olduğu, tek başına kullanıma karşın yan etkilerin daha düşük olduğu belirlendi. Etkinlik açısından kombinasyonların her ikisi de faz 2 denemelerde ümit vaat eden ürünler olarak belirlendi. ${ }^{[5,15]}$

\section{Bremelanotid (BMT)}

Sentetik bir melanokortin analoğudur. Melanokortin 3 ve 4 reseptörleri üzerinde agonistik etki ile cinsel istek ve uyarılmayı artırır. Başlangıçta intranazal uygulandı, etkin fakat hipertansif yan etki nedeniyle 2007'de çalışmalar durdu. 2016-2018 döneminde premenopozal kadınlarda subkütan uygulama ile hipertansif etkileri olmadan cinsel istek ve uyarılmayı artırdığını bildiren 2. ve 3. faz randomize, plasebo kontrollü klinik çalışmalar yayınladı. Mart 2018'de premenopozal kadınlarda HSDD tedavisi için FDA'ya sunuldu. ${ }^{[5,16,17]}$

\section{Bupropion-Trazodon Kombinasyonu (Lorexys)}

FDA onaylı iki antidepresanın (bupropion ve trazodonun) oral, hormonal olmayan, sabit dozlu bir birleşimidir. Bupropion, norepinefrin-dopamin geri alım inhibitörüdür. Trazodon, 5-HT1A kısmi agonisti, 5-HT2A antagonisti ve $\alpha 1$ antagonisti olarak etkinlik göstermektedir. Teorik olarak birlikte alındıklarında cinsel arzuyu artıracak ve inhibisyonu azaltacaktır. 2015'de premenopozal kadınlarda HSDD tedavisinde faz 2 a çalışmasında cinsel istek ve uyarılma cevabında anlamlı iyileşmeler raporlandı. HSDD'si olan kadınlarda kontrol grubunda alınan \%24'lük remisyon cevabına karşılık Lorexys ile \%58 cevap alınmış, FSFI skorlarında \%38'e karşılık \%76’lık cevap bildirilmiştir. Kombinasyon ile yan etki riski azaltılacak şekilde doz düzenlemesinin sağlanması da hedeflenmektedir. En sık görülen yan etki sedasyon idi, klitoral priapizm $(\% 3,8)$ de sık bildirilen yan etkilerdendi. Faz $2 \mathrm{~b}$ plasebo kontrollü çalışması devam etmektedir. ${ }^{[5,18]}$

\section{Fosfodiesteraz Tip 5 inhibitörleri}

2015'de FSD'de plasebo ve PDE5-i nin etkinliğini inceleyen 14 randomize kontrollü çalışmanın meta-analizi yayınlandı. Cinsel uyarılmada anlamlı iyileşme, orgazmik sıklık ve yoğunlukta anlamlı artış rapor edildi. Birçok hasta advers olaylar nedeniyle ilaç kullanımını durdurdu. Baş ağrısı, mide bulantısı, kızarma ve görme değişiklikleri en sık görülen yan etkilerdi. Günümüzde çalışmalar sonucunda varılan ortak kanaat kadın cinsel uyarılma ve orgazmik bozukluğunda PDE5-i yararlı olduğu, ancak yan etkilerinin pratik kullanımını sınırlandırdığı şeklindedir. Yan etkileri azaltma arayışları sürmektedir. 2017 de sildenafilin topikal bir formülasyonu ile faz 2 deneme tamamlandı ancak henüz sonuçları yayınlanmadı. ${ }^{[5,19]}$

\section{Prostaglandin E1}

Cinsel ilişkiden önce topikal olarak kullanılır, sistemik yan etkilere neden olmaz. Vajina, uterus ve klitoriste düz kas gevşemesine neden olur. İlave olarak duyusal afferent sinirlerin güçlenmesine imkan sağlar. Genital vazokonjesyon, vajinal kanlanma ve lubrikasyonda plaseboya kıyasla anlamlılığı sınırlı olumlu sonuçlar alınmış. FSD tedavisi 
için, Femprox markası ile transdermal alprostadil (sentetik PGE1) araştırma safhasındadır. 2013 de 3. faz çalışmanın sonuçları yayınlandı. Burada uyarılma ve orgazmik cevapta anlamlı iyileşme ve ağrıda anlamlı azalma rapor edildi, cinsel istek azlığında ise etkinlik belirlenmedi. ${ }^{[20,21]}$

\section{Umut Bağlanmıș Moleküller}

Doku selektif östrojen kompleksi (TSEC), vazoaktif intestinal peptid (VIP), NO donörleri ve tibolon. On yılı aşkındır gündemdeler, ancak FSD tedavisinde henüz kanıta dayalı bir başarı ve herhangi bir endikasyon için onaylanma rapor edilmedi. ${ }^{[5]}$

\section{Fitotörapetik ilaçlar}

Fitoterapi uygulamaları ile cinsel fonksiyon bozukluklarında etkin ve başarılı sonuçlar bildirilmiştir. Tribulus Terrestris, Yohimbin, Ginseng, Crocus Sativus, Maca, Ashwagandha, Mucuna Pruriens, Muira Puama, Ginkgo, Damiana, Black Cohosh vb. kullanım süresi, doz, uzun vadedeki sonuçları konusunda elimizde yeterli veri yoktur. Ürünlerin birçoğunda etki mekanizması tam olarak bilinmemektedir. Henüz kanıta dayalı kullanımları söz konusu değildir. ${ }^{[22]}$

\section{Farmakoterapi Dıșı Onaylı veya Faz Çalıșması Olan Tedaviler}

\section{Klitoral Vakum Cihazı (EROS)}

FDA tarafından Nisan 2000'de FSD tedavisi, özellikle cinsel uyarılma ve orgazm bozukluklarının tedavisi için onaylandı. İlişkiden bağımsız, haftada üç-dört kez, 10-15 $\mathrm{dk}$ süre ile 2 veya 3 ay düzenli klitoral ve bulbar bölgeye vakum uygulanması şeklinde kullanımı önerilir. Cinsel uyarılma cevabında $\% 80$, vajinal lubrikasyonda $\% 70$, orgazmik cevapta $\% 60$ ve toplam cinsel tatmin skorlarında $\% 90$ 'a varan iyileşmeler rapor edildi. ${ }^{[23,24]}$

\section{Transcutaneous Electrical Nerve Stimulation (TENS)}

Dorsal genital sinir stimülasyonu (DGNS) veya posterior tibial sinir stimülasyonu (PTNS) şeklinde uygulanabilir. Stimülasyon, $20 \mathrm{~Hz}$ de 30 dakika boyunca haftada bir kez olacak şekilde uygulanır. En iyi sonuçlar yaklaşık 12. haftada alınmaktadır. Cinsel uyarılma, lubrikasyon ve orgazm skorlarında sham grubuna göre oldukça anlamlı sonuçlar rapor edildi. Faz 3 çalışmaları planlanmaktadır. ${ }^{[25]}$

\section{Tedavi ile ilgili Dikkat Edilmesi Gereken Diğer Hususlar}

Belirlenmiş altta yatan bir neden varsa, eliminasyonu
Yaşam tarzı değişiklikleri

Düzenli egzersiz

Stresin azaltılması

İstirahat, gevşeme egzersizleri

Sigara, alkol ve madde alımının kontrol edilmesi

Cinsellikle ilgili eğitim/bilgilendirme

Partnerle ilişkide değişiklikler

Partner ile seks hakkında konuşma

Seks için farklı yer, zaman ve pozisyonların denenmesi

Psikoterapi/seks terapisi

Bilişsel davranışsal terapi (Masters B,Johnson V)

Pisikoanalitik model (S. Freud)

Hakem Değerlendirmesi

Dış bağımsız

Çıkar Çatışması

Yazarlar çıkar ilişkisi olmadığını beyan etmişlerdir.

Finansal Destek

Herhangi bir mali destek alınmamıştır.

Peer-review

Externally peer-reviewed.

Conflict of Interest

No conflict of interest was declared by the authors.

Financial Disclosure

No financial disclosure was received.

\section{KAYNAKLAR}

1. Berman JR, Berman L, Goldstein I. Female sexual dysfunction: incidence, pathophysiology, evaluation, and treatment options. Urology 1999;54:385-91. [CrossRef]

2. American Psychiatric Association. Diagnostic and Statistical Manual of Mental Disorders, 4th ed. (text revision). Washington, DC; 2000.

3. American Psychiatric Association. Diagnostic and statistical manual of mental disorders DSM-5. Arlington, TX: American Psychiatric Publishing; 2013.

4. Yılmaz E, Çöl M. Kanıta Dayalı Tip. J Clin Anal Med 2014;5:53742. [CrossRef]

5. Miller MK, Smith JR, Norman JJ, Clayton AH. Expert opinion on existing and developing drugs to treat female sexual dysfunction. Expert Opin Emerg Drugs 2018;23:223-30. [CrossRef]

6. Goldstein I, Kim NN, Clayton AH, DeRogatis LR, Giraldi A, Parish SJ, et al. Hypoactive sexual desire disorder: international society for the study of women's sexual health (ISSWSH) expert consensus panel review. Mayo Clin Proc 2017;92:114-28. [CrossRef]

7. Lodise NM. Female sexual dysfunction: a focus on flibanserin. Int J Womens Health 2017;9:757-67. [CrossRef]

8. Portman DJ, Brown L, Yuan J, Kissling R, Kingsberg SA. Flibanserin in postmenopausal women with hypoactive sexual desire disorder: results of the PLUMERIA study. J Sex Med 2017;14:834-42. [CrossRef]

9. Rioux JE, Devlin MC, Gelfand MM, Steinberg WM, Hepburn DS. $17 \beta$-estradiol vaginal tablet versus conjugated equine estrogen vaginal cream to relieve menopausal atrophic vaginitis. Menopause 2018;25:1208-13. [CrossRef] 
10. Constantine GD, Simon JA, Pickar JH, Archer DF, Kushner H, Bernick B, et al.; REJOICE Study Group. The REJOICE trial: a phase 3 randomized, controlled trial evaluating the safety and efficacy of a novel vaginal estradiol soft-gel capsule for symptomatic vulvar and vaginal atrophy. Menopause 2017;24:409-16. [CrossRef]

11. Imvexxy - Another Estradiol Vaginal Insert for Dyspareunia. JAMA 2019;321:506-7. [CrossRef]

12. Goldstein I, Simon JA, Kaunitz AM, Altomare C, Yoshida Y, Zhu $\mathrm{J}$, et al. Effects of ospemifene on genitourinary health assessed by prospective vulvar-vestibular photography and vaginal/vulvar health indices. Menopause 2019;26:994-1001. [CrossRef]

13. Labrie F, Archer DF, Koltun W, Vachon A, Young D, Frenette L, et al.; VVA Prasterone Research Group. Efficacy of intravaginal dehydroepiandrosterone (DHEA) on moderate to severe dyspareunia and vaginal dryness, symptoms of vulvovaginal atrophy, and of the genitourinary syndrome of menopause. Menopause 2016;23:243-56. [CrossRef]

14. Osborne V, Layton D, Shakir SA. Implications of off-label use: An example from the final results of an observational cohort study on Intrinsa ${ }^{\circ}$ (testosterone patch). Post Reprod Health 2014;20:48-54. [CrossRef]

15. Tuiten A, van Rooij K, Bloemers J, Eisenegger C, van Honk J, Kessels R, et al. Efficacy and safety of on-demand use of 2 treatments designed for different etiologies of female sexual interest/arousal disorder: 3 randomized clinical trials. J Sex Med 2018;15:201-16. [CrossRef]

16. Clayton AH, Althof SE, Kingsberg S, DeRogatis LR, Kroll R, Goldstein I, et al. Bremelanotide for female sexual dysfunctions in premenopausal women: a randomized, placebo-controlled dosefinding trial. Womens Health (Lond) 2016;12:325-37. [CrossRef]

17. Clayton HA, Kingsberg S, Simon J, Jordan R, Lucas J. the investigational drug bremelanotide for Hypoactive Sexual Desire Disorder (HSDD): efficacy analyses from the RECONNECT studies. J Sex Med 2018;15(Suppl 1):S7-8. [CrossRef]
18. Pyke RE, Katz M, Segraves RT, Sitchon N. Phase IIa study of a proprietary combination of bupropion and trazodone for hypoactive sexual desire disorder (HSDD) in premenopausal women: novel responder and remitter results. Poster presentation at the Annual Meeting of the American Society of Clinical Psychopharmacology, Miami, FL, June 22-25, 2015.

19. Gao L, Yang L, Qian S, Li T, Han P, Yuan J. Systematic review and meta-analysis of phosphodiesterase type 5 inhibitors for the treatment of female sexual dysfunction. Int J Gynaecol Obstet 2016;133:139-45. [CrossRef]

20. Goldstein I, Qinping L, Damaj B, et al. Phase 3 clinical trial results with femprox treatment in FSAD patients show correlation of arousal with both lubrication and orgasm but not with desire. J Sex Med 2013;10:164.

21. Belkin ZR, Krapf JM, Goldstein AT. Drugs in early clinical development for the treatment of female sexual dysfunction. Expert Opin Investig Drugs 2015;24:159-67. [CrossRef]

22. Aygin D, Gül A, Yaman Ö, Cengiz H. Kadın cinsel fonksiyon bozukluklarında fitoterapi. Androl Bul 2018;20:126-32. [CrossRef]

23. Billups KL, Berman L, Berman J, Metz ME, Glennon ME, Goldstein I. A new non-pharmacological vacuum therapy for female sexual dysfunction. J Sex Marital Ther 2001;27:435-41. [CrossRef]

24. Wilson SK, Delk JR, Billups KL. Treating symptoms of female sexual arousal disorder with the Eros-Clitoral Therapy Device. J Gend Specif Med 2001;4:54-8.

25. Zimmerman LL, Gupta P, O'Gara F, Langhals NB, Berger MB, Bruns TM. Transcutaneous electrical nerve stimulation to improve female sexual dysfunction symptoms: a pilot study. Neuromodulation 2018;21:707-13. [CrossRef] 